\title{
Comparison of fatigue behaviour of eight different hip stems: a numerical and experimental study
}

\author{
Mahmut Pekedis, Hasan Yildiz
}

Mechanical Engineering Department, Engineering Faculty, Ege University, Izmir, Turkey.

Email: mahmut.pekedis@ege.edu.tr; hasan.yildiz@ege.edu.tr

Received 14 March 2011; revised 21 April 2011; accepted 23 May 2011.

\begin{abstract}
In this study, finite element analysis was used to investigate the fatigue behavior of eight different hip stems. All of the prostheses investigated in the analysis are already being used in Turkish orthopaedic surgery. All stems were compared with each other in terms of fatigue, deformation and safety factors. Primary analysis was applied on three of the stems, which were tested experimentally. It was observed that the simulation and the experimental results are in good agreement with each other. After determining the reliability of the numerical method, the analysis was applied on all other stems. To obtain a more realistic simulation, boundary conditions were applied according to standards specified in the ISO 7206-4 standard. Three different types of materials were selected during analysis. These materials were Ti6Al-4V, cobalt chrome alloy and 316L. Minimum fatigue cycles, critical fatigue areas, stresses and safety factor values have been identified. The results obtained from the finite element analysis showed that all stems were safe enough in terms of fatigue life. As a result of fatigue analysis, all stems have been found to be successful, but some of them were found to be better than the others in terms of safety factor. The current study has also demonstrated that analysing hip stems with the finite element method (FEM) can be applied with confidence to support standard fatigue testing and used as an alternative. Further studies can expand the simulations to the clinical relevance due to complex physical relevance.
\end{abstract}

Keywords: Hip Stem; Fatigue; The Finite Element Method

\section{INTRODUCTION}

A degenerated organ in the human body can be replaced by the surgical implantation of replacement components called biological parts. Hip stems are the replacement parts that are successfully applied to the patients affected by hip disorders and fractures. John Charnley is known as the inventor of artificial hip prosthesis with low friction [1]. Total hip arthroplasticity (THA) is applied in a large number worldwide for the treatment of osteoarthritis in hip joints [2-4]. Despite THA surgeries being successful in recent years, $10 \%$ of them still fail within 9 10 years. These failures are caused by many reasons. The most important reasons are dislocations of the ball in the liner or bone cement not cohering to the hip stem [5]. The other factors are conflicts in physical properties of the implant and the body, biocompatibility, deterioration, design failure and surgical procedures. If the shape of a stem leads to high stresses in fixation areas, fracture in the short term or fatigue failure in the long term is quite likely to occur. Several researchers have investigated the stress and fatigue behavior of implants under static body load conditions.

The forces applied to the prosthesis during human activity generate dynamic stresses varying in time and may result in fatigue failure of an implant. Therefore, it is important to ensure that hip prostheses withstand against fatigue failure. Fatigue testing of total hip joints must be implemented as a part of the design approval of prostheses. In order to ensure this, the stems should be tested according to international testing standards [6] in which hip stems should survive a minimum cycle of 5 million.

Testing of prosthesis experimentally requires a long time and high costs. To obtain an optimal prosthesis without excessive time and costs, numerical testing could be used as a powerful tool. In general, the finite element method (FEM) is used in the analysis of biomedical components. In recent years, the FEM combined with mechanical testing of orthopaedic implants is be ginning to be accepted by the Food and Drug Administration during submission for pre-market approval [7].

In the literature, finite element analysis was used to simulate fatigue damage of implants under static body 
weight and dynamic walking load [8]. The results of finite element analysis have been compared to the material fatigue strength $[9,10]$. Stress distribution and design optimisation on a conical stem of hip prosthesis were determined using Ti6A4V and UHMWPE material [11]. Fatigue tests of hip models with different activities, such as sit-to-stand movements and upstairs, downstairs and climbing were conducted [12]. A three-dimensional stress analysis was performed to determine stress distribution in the cement mantle cross-section of the hip replacements [13].

The performance of a hip stem depends on many parameters including material type, stem length, cross section shape, neck length, neck angle, ball diameter and cement use. In this study, finite element analysis according to the ISO 7206-4 test procedure [6] was implemented to analyse eight hip stems already in use in terms of fatigue life, stem stress and displacement.

The analysis on eight stems was implemented by using the ANSYS Workbench package. The force applied on the ball ranges from $300-2300 \mathrm{~N}$ as defined in the ISO 7206-4 test standard. Fatigue analysis was primarily carried out on some stems that are tested experimenttally. The results of experimental tests and finite element analyses were compared. According to the comparison of the results, the values obtained in the FEM and the tests agree with each other in terms of fatigue cycle and deflection. After determining the reliability of the method, the new analyses were performed for the other hip stems to determine the stem that may have the highest fatigue life. The type of material used in stems is also an effective fatigue parameter. The most commonly used materials in implants are metals, polyethylene polymers, ceramics and composites [14]. In this study, three kinds of materials were used in simulation to determine the fatigue life change related to material variations. Ti6Al4V, Cobalt Chrome Molybdenum (Co-Cr-Mo) alloy and $316 \mathrm{~L}$ were used in analysis to determine the fatigue behavior of the stems.

\section{MATERIALS AND METHODS}

\subsection{Hip Stem Models}

All hip stem models investigated in this study are shown in Figure 1. The eight models made of different materials (Ti6Al4V, Co-Cr-Mo and 316L) were analysed numerically. It is well known that shapes with smooth surfaces reduce stress concentration and increase fatigue life. As such, the investigated stems were considered to have smooth surfaces. The most important factor for determining the fatigue life of a stem is the stress distribution. Another factor that is the type of material the stem has been produced from has the potential to affect the stem loosening and fracture. The cylinder in the

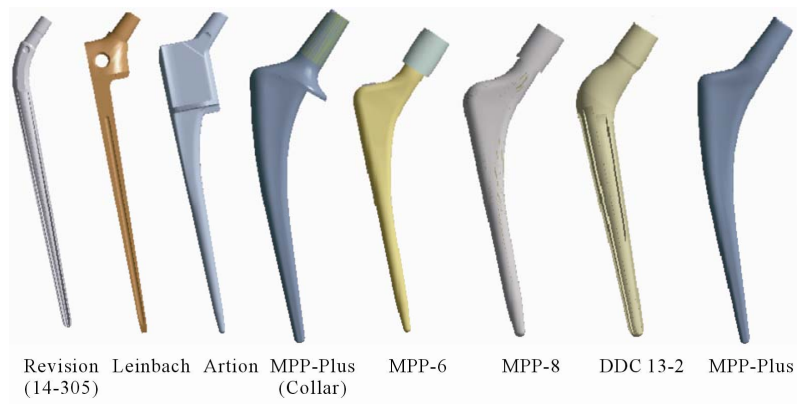

Figure 1. Hip stem models.

model applies the load to the ball in a vertical direction, stem and spherical ball and bone cement for a realistic analysis.

\subsection{Experimental Test Method}

The three stems were tested according to the ISO 7206-4 fatigue test standard. These tests determine the endurance properties of femoral components and simulate the dynamic loading of hip stems. The orientation of specimen in experimental study is shown in Figure 2.

The steps of the fatigue test can be listed as: determining the parameters according to Table 1, supporting the test specimen in the position until the embedding has sufficient hardness to support the specimen unaided, mounting of the stem on to the test machine, adjusting the load levels so that the cross head can apply required load to the test specimen, applying the force to the stem by testing machine and obtaining the results. The parameters related to the placement of the stem in the text setup according to the test standard are shown in Table 2.

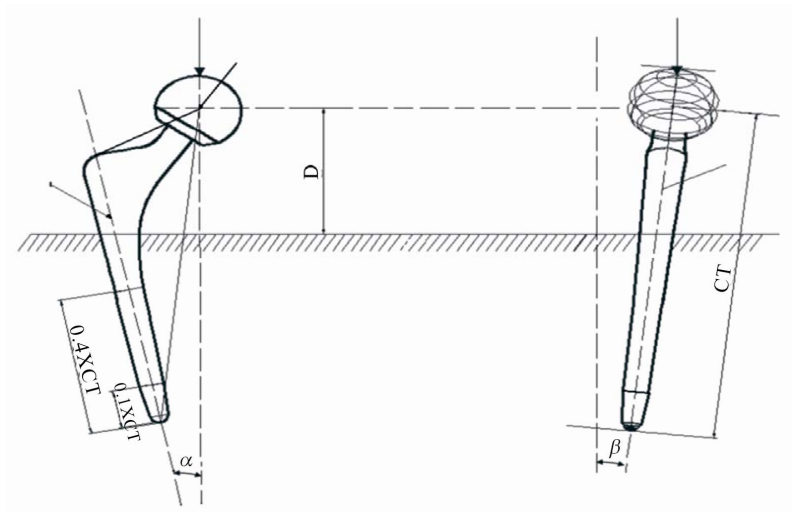

Figure 2. Orientation of specimen in experimental study [7].

Table 1. Parameters for alignment of the test specimen.

\begin{tabular}{cccc}
\hline CT $(\mathbf{m m})$ & $\mathbf{D} \pm \mathbf{2} \mathbf{~ m m}$ & $\boldsymbol{\alpha} \pm \mathbf{1}$ degree & $\boldsymbol{\beta} \pm \mathbf{1}$ degree \\
\hline up to and including 200 & $0.4 \times \mathrm{CT}$ & 10 & 9 \\
more than 200 & CT-100 & 0 & 4 \\
\hline
\end{tabular}




\subsection{Finite Element Analysis}

The FEM was used to compute the fatigue life, stress distribution and critical location of the stems. The material properties, loading history and geometry of the stems were input data to the analysis (Figure 3).

In this study, stems numbered from 1 to 8 were analysed by using the FEM according to the ISO 7206-4 test conditions. The stems were embedded in cement at a specific angle as shown in Table $\mathbf{1}$ in frontal plane. Ball, stem, cylinder and cement were meshed using a higher order three dimensional solid element (SOLID 187) which is suitable for modeling the complex geometry. Contact and sliding between ball-stem, stem-cement and ball-cylinder interfaces modeled with contact (CONTA 174 and TARGE 170) elements. The contact elements themselves overlay the solid elements describing the boundary of a deformable body and that are in contact with the target surface. The average number of elements of the total models consisting of stem, ball, bone cement and loading part is 15296 as shown in Table 3.

The average number of elements of the total models consisting of stem, ball, bone cement and loading part is 15296 as shown in Table 3. The area of the stem around cement and the ball modeled with a fine mesh with the average of 2640 elements. Contact elements were used between the stems and cement.

Table 2. Test setup dimensions for currently used stems.

\begin{tabular}{ccccccc}
\hline No & Prosthesis & $\begin{array}{c}\text { Length } \\
(\mathbf{m m})\end{array}$ & $\begin{array}{c}\text { Cone tip } \\
\text { Diameter } \mathbf{( m m})\end{array}$ & $\begin{array}{c}\mathbf{D} \\
(\mathbf{m m})\end{array}$ & $\boldsymbol{\alpha}^{(\mathbf{o})}$ & $\boldsymbol{\beta}^{(\mathbf{0})}$ \\
\hline 1 & Revision & 225 & 14 & 90 & 11 & 9 \\
2 & Leinbach & 210 & 12 & 84 & 10 & 4 \\
3 & Artion & 115 & 9 & 46 & 10 & 9 \\
4 & MPP-Plus & 137 & 12 & 55 & 11 & 4 \\
5 & MPP-6 & 135 & 12 & 54 & 11 & 4 \\
6 & MPP-8 & 140 & 12 & 56 & 10 & 4 \\
7 & DDC 13-2 & 90 & 12 & 90 & 10 & 4 \\
8 & MPP Plus & 137 & 12 & 55 & 11 & 4 \\
\hline
\end{tabular}

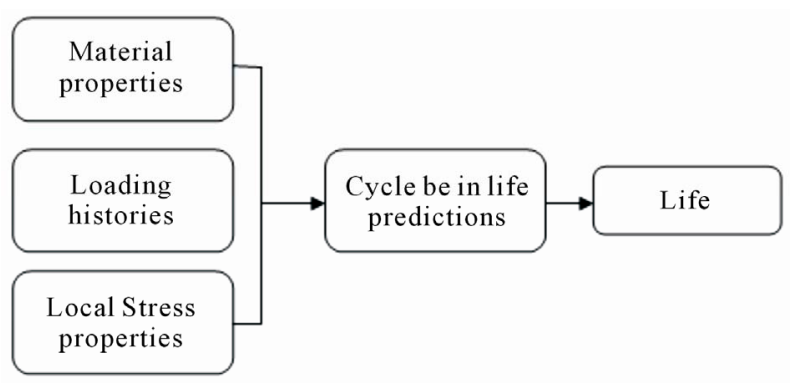

Figure 3. Fatigue analysis prediction strategy.
The load was applied in two steps. First a vertical force was increased from 0 to the maximum force of $2300 \mathrm{~N}$ acting at the centre of the cylinder (Figure 4). In the second step the load was decreased to the $300 \mathrm{~N}$ and stem was allowed to deflect backward to the original position. The cylindrical surface and the bottom of the bone cement were fixed in all directions. Three different materials were used in the finite element analysis. The alternating stress versus number of cycle graphs were used to determine the stress range, minimum and maximum stresses, displacement and fatigue life were investtigated on stems. The material of ball and the upper cylindrical part was selected stainless steel while the stems had three different materials (Table 4).

The alternating stress versus the number of cycle diagrams used in the fatigue analysis were obtained from literature and are shown in Figures 5 and 6.

Table 3. Number of elements.

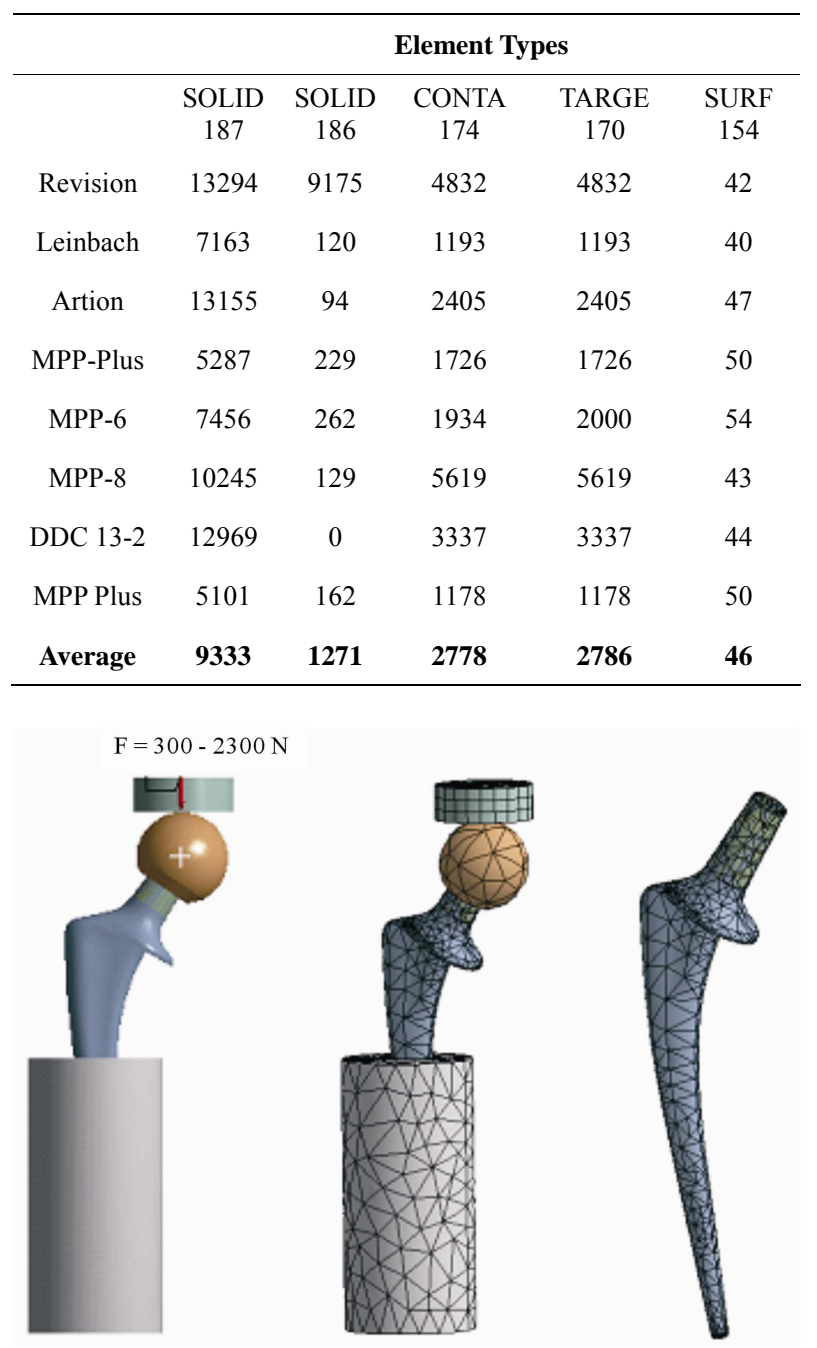

Figure 4. Finite element mesh, loading and boundary conditions. 
Table 4. Mechanical properties of materials used in analysis.

\begin{tabular}{ccccc}
\hline Material & $\begin{array}{c}\text { Elastic } \\
\text { Modulus } \\
\text { (GPa) }\end{array}$ & $\begin{array}{c}\text { Poisson's } \\
\text { Ratio }\end{array}$ & $\begin{array}{c}\text { Yield } \\
\text { Strength } \\
\text { (MPa) }\end{array}$ & $\begin{array}{c}\text { Ultimate } \\
\text { Strength } \\
\text { (MPa) }\end{array}$ \\
\hline Ti-6Al-4V [15] & 113.8 & 0.33 & 880 & 950 \\
$\begin{array}{c}\text { Co-Cr-Mo Alloy } \\
{[16,17]}\end{array}$ & 234.8 & 0.30 & 720 & 1010 \\
$\begin{array}{c}\text { Cement } \\
\text { (PMMA) [18,19] }\end{array}$ & 2.8 & 0.30 & 12.5 & 27.6 \\
$\begin{array}{c}\text { Stainless Steel } \\
\text { (316L) [20,21] } \\
\begin{array}{c}\text { Structural } \\
\text { Steel[22] }\end{array}\end{array}$ & 195.0 & 0.30 & 170 & 480 \\
\hline
\end{tabular}

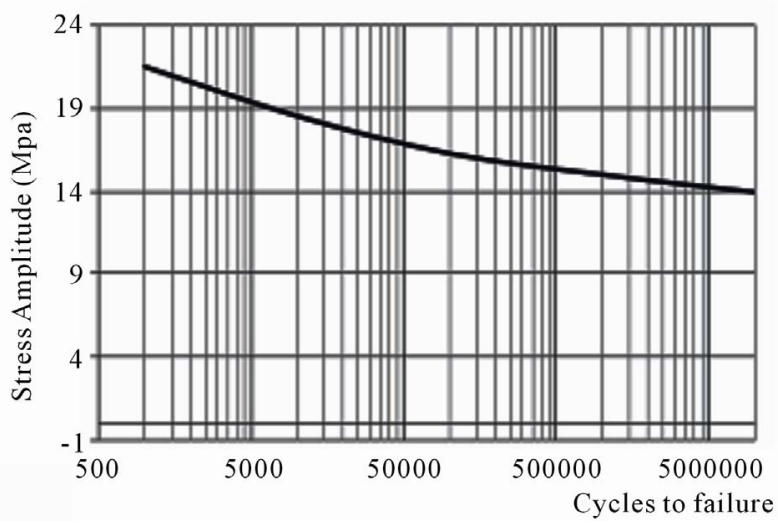

(a)

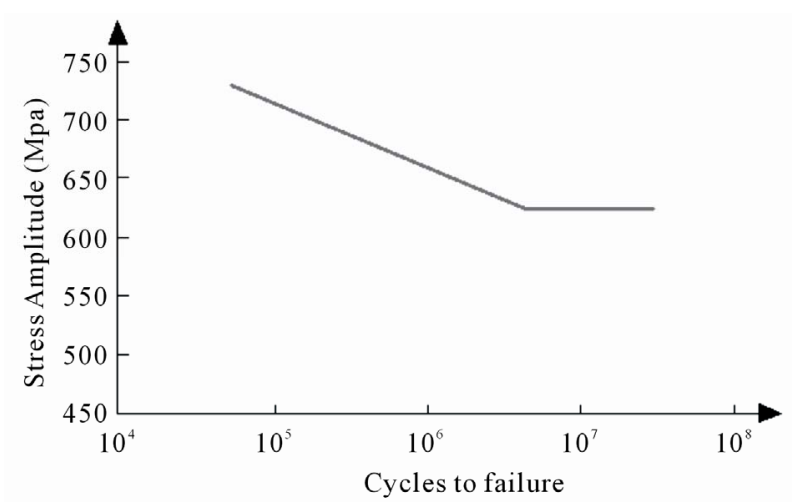

(b)

Figure 5. S-N curves used for (a) bone cement (PMMA) [23]; (b) CoCrMo [24].

\subsection{Fatigue Analysis}

The finite element method was used to evaluate all of the stems in terms of the fatigue life safety factor. Fatigue lives of stems were calculated based on the Goodman mean-stress fatigue theory.

Mean and alternating stresses in the Goodman fatigue life theory are defined as:

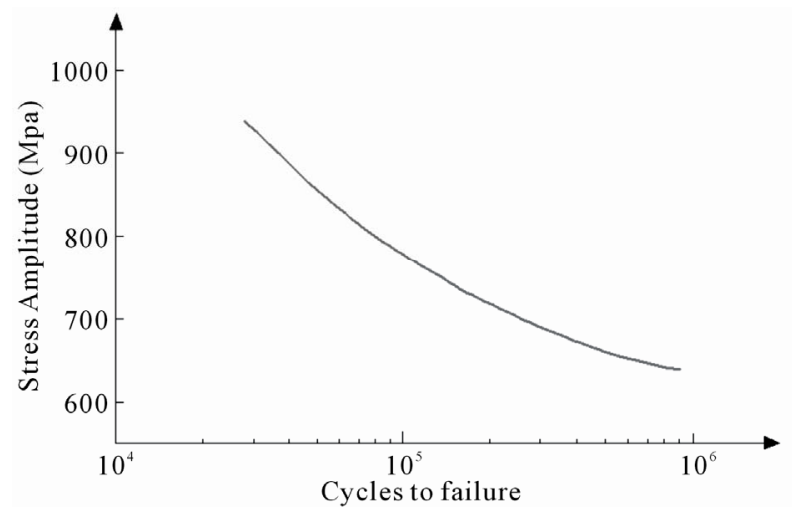

(a)

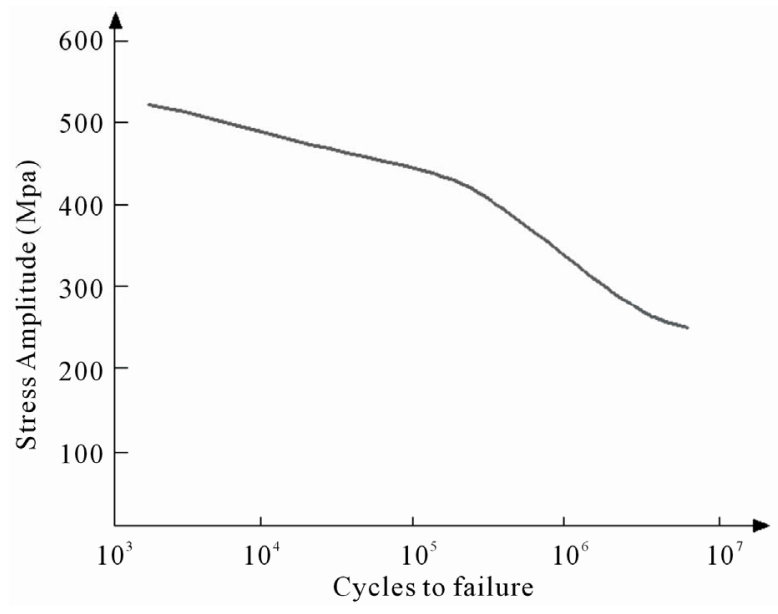

(b)

Figure 6. S-N curves used for (a) 316L [25]; (b) Ti4A16V [21].

$$
\begin{gathered}
\sigma_{m}=\frac{\sigma_{\max }+\sigma_{\min }}{2} \\
\sigma_{a}=\frac{\sigma_{\max }-\sigma_{\min }}{2}
\end{gathered}
$$

respectively. According to the modified Goodman theory the relation between mean and alternation stress is:

$$
\frac{\sigma_{a}}{S_{e}}+\frac{\sigma_{m}}{S_{u t}}=\frac{1}{n}
$$

where $S_{e}$ is the endurance limit and $S_{u t}$ is the tensile strength of the material.

The fatigue factor of safety becomes as [26]

$$
n_{f}=\frac{1}{\frac{\sigma_{a}}{S_{e}}+\frac{\sigma_{m}}{S_{u t}}}
$$

\section{RESULTS AND DISCUSSIONS}

All stems were analysed with the FEM by applying load and boundary condition defined in ISO 7206-4 standard. 
First, three specimens (MPP-6, MPP-8 and MPP Plus) were tested experimentally. Experimental and numerical fatigue life behaviours of MPP Plus and the stem for different loadings are given in Table 5. The average of difference between numerical and experimental results was found to be $13 \%$.

Both experimental and numerical results of the stem MPP-6 fatigue for different loading, embedding level and applied cycle are given in Table 6. No damage was seen when the stem was embedded $60.5 \mathrm{~mm}$ in the cement, with the load range of $300-1700 \mathrm{~N}$ after five million cycles. Cycle-deflection graph is given in Figure 7 for the loading range of $300-1700 \mathrm{~N}$ for the stem MPP-6 made of Co-Cr-Mo. It can be seen that both numerical and experimental results obtained from tests agree with each other.

Cycle-deflection graph is given in Figure 7 for the loading range of 300-1700 $\mathrm{N}$ for the stem MPP-6 made of Co-Cr-Mo. It can be seen that both numerical and experimental results obtained from tests agree with each other. In the same way, a cycle-deflection graph is seen in Figure 8 for the loading range of $300-2800 \mathrm{~N}$ for the stem MPP-8. The deflection varies from 0.09 to 0.75 $\mathrm{mm}$ as seen in Figure 8.

All stems having different cross sectional geometries were subjected to a force ranged from 300 to $2300 \mathrm{~N}$.

Table 5. Experimental and numerical results for MPP-Plus made of CrCoMo.

\begin{tabular}{cccc}
\hline $\begin{array}{c}\text { Minimum } \\
\text { Load (N) }\end{array}$ & $\begin{array}{c}\text { Maximum } \\
\text { Load (N) }\end{array}$ & $\begin{array}{c}\text { Cycles } \\
\text { (Experimental) }\end{array}$ & $\begin{array}{c}\text { Cycles } \\
\text { (Experimental) }\end{array}$ \\
\hline 360 & 2300 & 998494 & 1232545 \\
360 & 2800 & 996343 & 998717 \\
490 & 3800 & 764778 & 869871 \\
\hline
\end{tabular}

Table 6. Experimental and Numerical Results for MPP-6 made of CrCoMo.

\begin{tabular}{ccccc}
\hline $\begin{array}{c}\text { Embedding } \\
\text { Level (mm) }\end{array}$ & Load (N) & Cycles & $\begin{array}{c}\text { Result } \\
\text { (Experimental) }\end{array}$ & $\begin{array}{c}\text { Result } \\
\text { (FEM) }\end{array}$ \\
\hline 80.5 & $300-1100$ & $10^{6}$ & No Failure & No Failure \\
& $300-1300$ & $10^{6}$ & No Failure & No Failure \\
& $300-1500$ & $10^{6}$ & No Failure & No Failure \\
79.0 & $300-1700$ & $10^{6}$ & No Failure & No Failure \\
& $300-1900$ & $10^{6}$ & No Failure & No Failure \\
& $300-2100$ & $10^{6}$ & No Failure & No Failure \\
& $300-2300$ & $5 \times 10^{6}$ & No Failure & No Failure \\
61.2 & $300-1700$ & $5 \times 10^{6}$ & No Failure & No Failure \\
& $300-1700$ & $5 \times 10^{6}$ & No Failure & No Failure \\
\hline
\end{tabular}

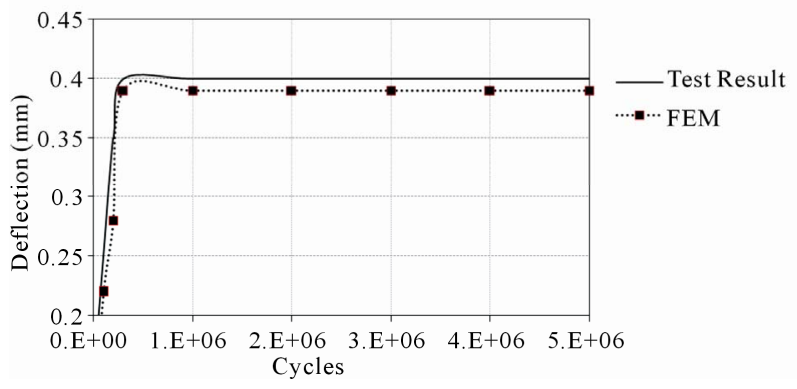

Figure 7. Cycle-deflection relationship for MPP-6: the force is ranged from $300 \mathrm{~N}$ to $1700 \mathrm{~N}$.

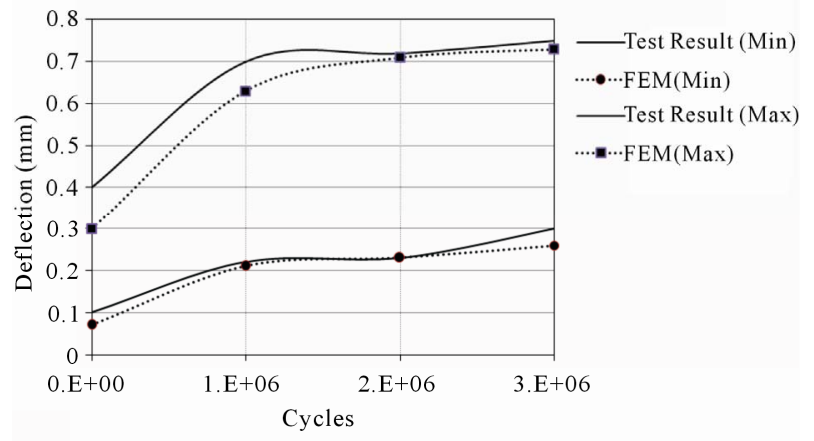

Figure 8. Cycle-deflection relationship for MPP-8: the force is ranged from $300 \mathrm{~N}$ to $2800 \mathrm{~N}$.

The force was applied to the upper cylinder to get a distributed force on the femoral head (Figure 4).

It was observed in Figures $\mathbf{7}$ and $\mathbf{8}$ that the numerical and the experimental results are comparable to each other. The two stems that had the highest stresses were MPP Plus and MPP Plus with collar. DDC 13-2 had the lowest amount of vertical displacement. The best stem among the eight was found to be Revision. The best stem shape for fatigue analysis under given loading was found to be Revision, made of Co-Cr-Mo (Figures 9-11).

Safety factor distributions were given in Figures 1214 when different materials were used. Critical safety factor values are usually seen in the medial of the stems and at the stem-cement interface. All of the analyses involving titanium alloy cases had the highest amount of displacements. This is because elastic modulus of $\mathrm{Ti}$ alloy is lower than that of Co-Cr-Mo and $316 \mathrm{~L}$.

\section{CONCLUSIONS}

Results obtained from the finite element analysis show that all stems investigated in this study are safe against fatigue failure. The best stem shapes in terms of fatigue life under given loading have been found to be Revision, Leinbach, and Artion. These stems had the highest safety factors. Revison was found to be about three times safer than MPP Plus. When the geometry of the implant is complex, high stresses will develop because of stress 
concentrations. The maximum stress was seen in MPP Plus. The location where the maximum stress occurred for all stems were on lateral side of the implant.

This study shows that embedding level has an important role in fatigue life (Table 6). Safety factors decrease when decreasing the level of embedding. No failures or

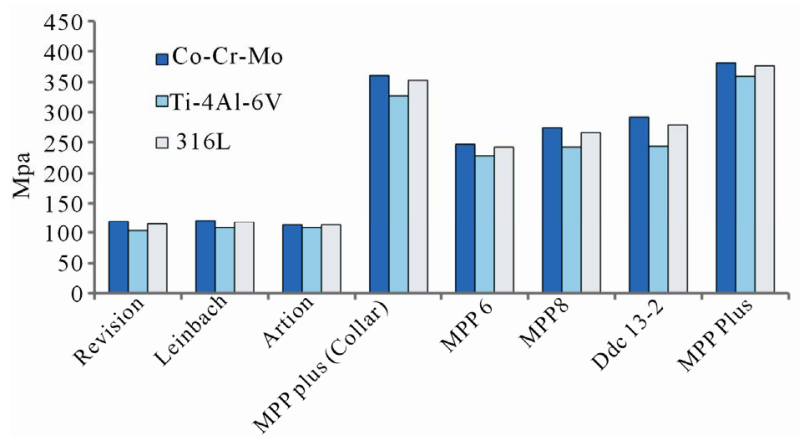

Figure 9. Maximum von misses stresses in all stems for different stem materials.

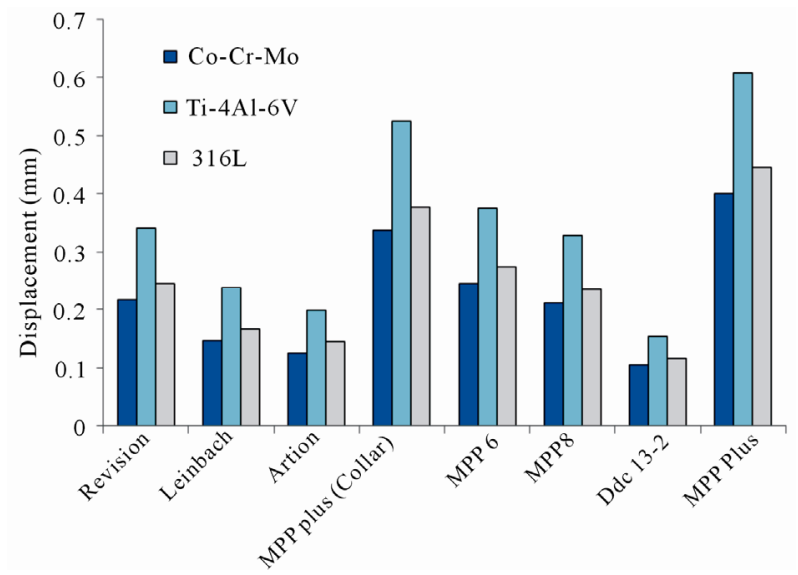

Figure 10. Maximum vertical displacement in all stem for different stem materials.

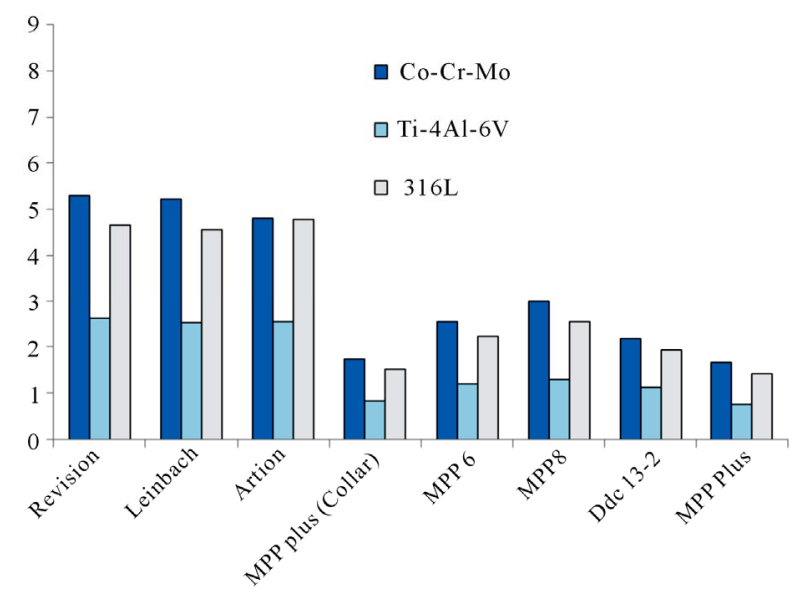

Figure 11. Minimum safety factor in all stem for different stem materials.

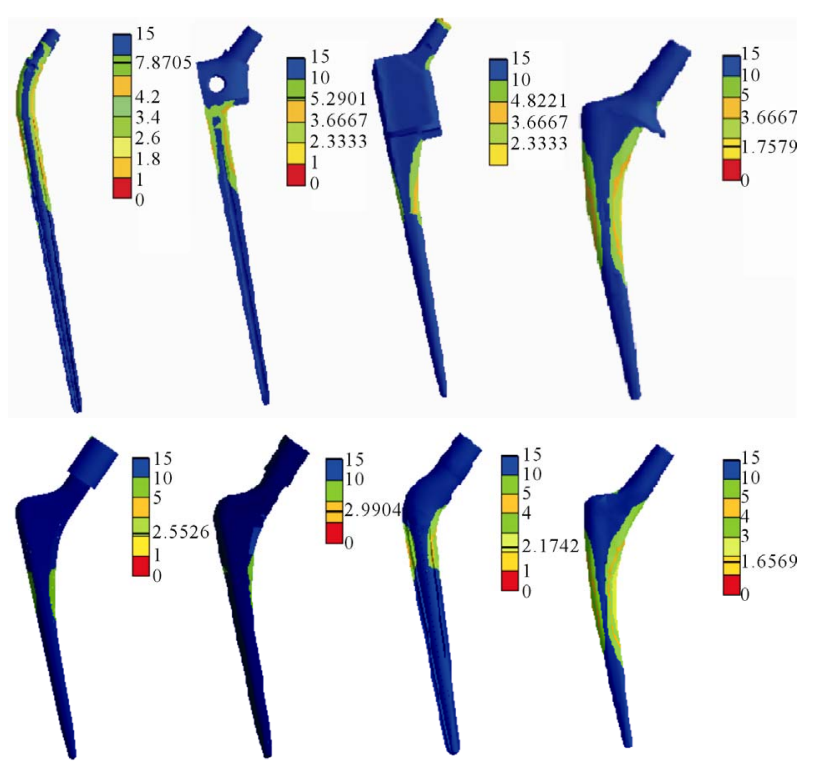

Figure 12. Safety factor distributions for stems 1 to 8 made of CoCrMo.

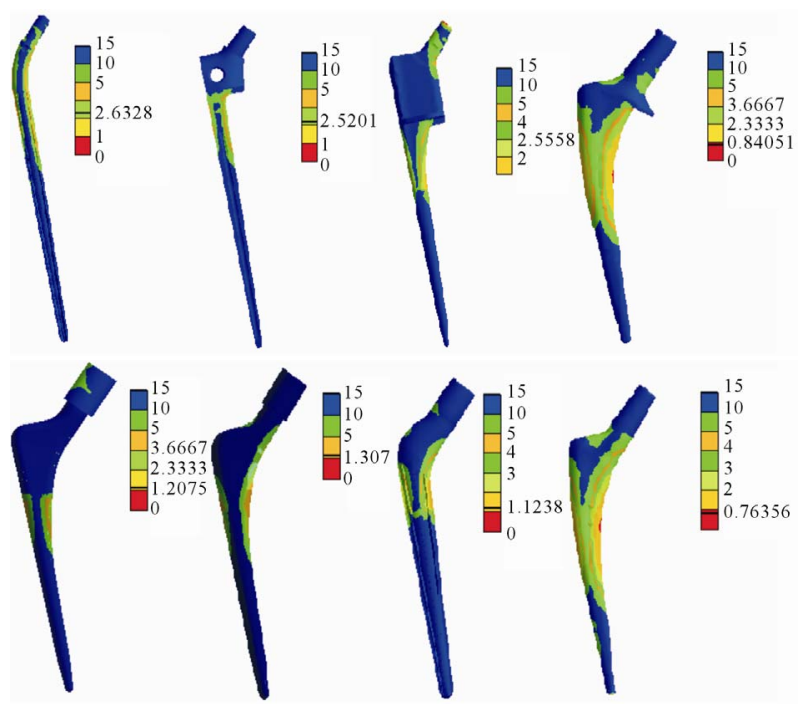

Figure 13. Safety factor distribitions for stems 1 to 8 made of Ti6AL4V.

fractures were seen experimentally at different load levels and cycles. According to the both experimental and finite element results when using $\mathrm{Co}-\mathrm{Cr}-\mathrm{Mo}$ as a material for MPP-6, MPP-8 or MPP Plus, there is no failure at $5 \times 106$ cycles. The minimum safety factor was observed in MPP Plus.

When the materials used for stems were compared in terms of fatigue life; the highest values were found in Co-Cr-Mo stems while the lowest values were seen in stems made of Ti6Al4V. The safety factors were found close to each other in Revision, Artion and Leinbach. Similarly, MPP-6, DDC 13-2 and MPP Plus were deter- 


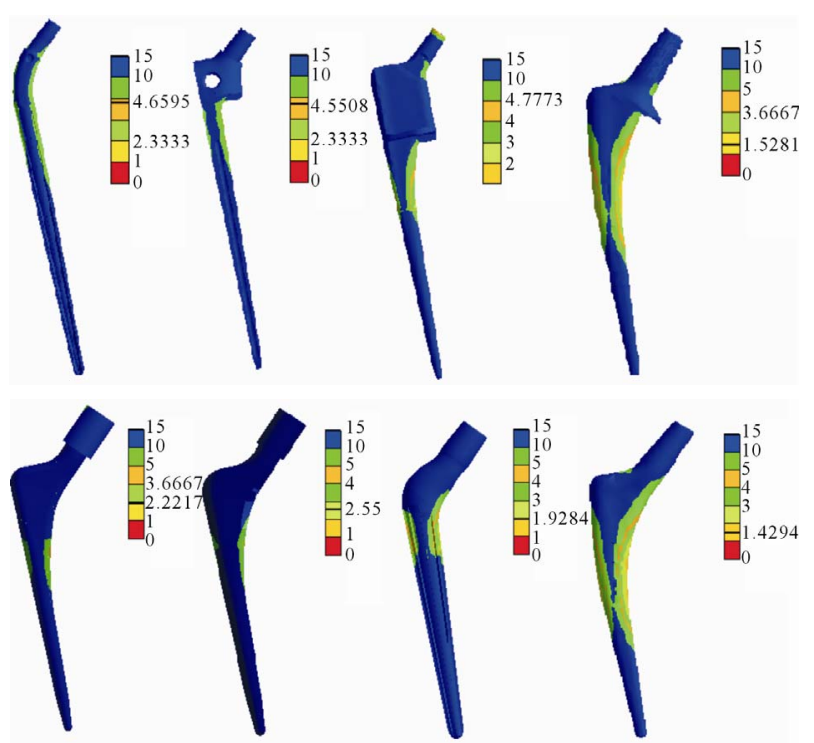

Figure 14. Safety factor distributions for stems 1 to 8 made of of $316 \mathrm{~L}$.

mined to have safety factors close to each other. Stems which have higher safety factors were found to have smaller deflections and stresses. Analysis results showed that sorting stems from high to low safety factors is as Revision, Leinbach, Artion, MPP-8, MPP-6, DDC 13 - 2, MPP Plus (collar) and MPP plus (Figures 9-11). MPP Plus (collar) has the same stem size and cross section with MPP Plus.

The only difference between MPP Plus (collar) and MPP Plus is the collar in the proximal-medial region of the stem. This collar reduces the bending moment due the vertical loads acting on the stem and it allows the moment to be transferred directly to the distal femur. Additionally this provides an increase of approximately $13 \%$ in critical safety factor value and results higher fatigue life in working conditions. Consequently the stress shielding in the proxi-medial femoral bone will be reduced due to the increase in load values.

The current study has demonstrated that numerical fatigue analysis can be applied with confidence to support standard fatigue test. Hip stems can be designed with the aid of the finite element method before they are manufactured or implanted in the patient. Further studies could expand to understand of these complex loading and environments on the fatigue life of hip stems.

\section{ACKNOWLEDGEMENTS}

The authors would like to thank Hipokrat A.S for supplying hip stems.

\section{REFERENCES}

[1] Garbuz, D.S., Tanzer, M., Greidanus, N.V., Masri, B.A. and Duncan, C.P. (2010) The John Charnley Award. Clin
Orthop Relat Res, 468, 318-332. doi:10.1007/s11999-009-1029-x

[2] Affatato, S., Mattarozzi, A., Taddei, P., Robotti, P., Soffiatti, R., Sudanese1, A. and Toni, A. (2003) Investigation on the wear behavior of the temporary PMMAbased hip Spacer-G. A Proceedings of the Institution of Mechanical Engineers, Part H: Journal of Engineering in Medicine, 217, 1-8.

[3] Fusaro, I., Mari, G. and Bilotta, T. W. (1996) Trattamento riabilitativo nel reimpianto e nell'espianto di protesi d'anca. In Artroprotesi e Riabilitazione. XXIV Congresso Nzionale SIMFER, Bologna, 102-113.

[4] Bauer, T.W. and Schils, J. (1999) The pathology of total joint arthroplasticity. II, Mechanics of implant failulure. Skeletol Radiology, 28, 483-497. doi:10.1007/s002560050552

[5] Scifert, C.A. (1999) Finite element investigation into biomechanics of total artificial hip dislocation. Ph.D. Thesis, University of Iowa.

[6] ISO 7206-4. (2002) Determination of endurance properties of stemmed femoral components, implants for Surgery. Partial and total hip joint prostheses, International Organization for Standardization.

[7] Ploeg, L., Bürgi, M. and Wyss, U.P. (2009) Hip stem fatigue test prediction. International journal of fatigue, 31, 894-905. doi:10.1016/j.ijfatigue.2008.10.005

[8] Kayabaşı, O. and Ekici, B. (2007) The effects of static, dyna- mic and fatigue behavior on three-dimensional shape optimization of hip prosthesis by finite element method. Materials \& Design, 28, 2269-2277. doi:10.1016/j.matdes.2006.08.012

[9] Viceconti, M., Mc, B.P., Toni, A. and Giunti, A. (1996) FEM analysis of the static stresses induced in a THR femoral components during a standardized fatigue test. In: Middleton, J., Jones, M. and Pandi, G. Eds., Second International Symposium on Computer Methods in Biomechanics and Biomedical Engineering, London. 57-66.

[10] Akay, M. and Aslan, N. (1995) An estimation of fatigue life for a carbon fibre/polyesther ketone hip joint prosthesis. Proceedings of the Institute of Mechanical Engineers Part H: Journal Engineering in Medicine, 209, 93-103. doi:10.1243/PIME_PROC 1995_209 $325 \quad 02$

[11] Sivasankar, M., Chakraborty, D. and Dwivedy, S.K. (2006) Fatigue analysis of artificial hip joints for different materials. XVI Conference of Society for Biomaterials and Artificial Organs-India on Biomaterials, Tissue Engineering and Medical Diagnostics, Delhi, 24-26 February 2006.

[12] Styles, C.M., Evans, S.L. and Gregson, P.J. (1998) Devolopment of fatigue lifetime predictive test methods for hip implants: Part 1, Test methodology. Biomaterials, 19, 1057-1065. doi:10.1016/S0142-9612(98)00031-3

[13] McCormack, B.A.O., Prendergast, P.J. and Dwyer, B.O. (1999) Fatigue of cemented hip replacements under torsional loads. Fatigue fracture engineering material structure, 22, 33-40.

[14] Yildiz, H., Ha, S.Y. and Chang, F.K. (1998) Composite hip prosthesis design. I. Analysis. Journal of Biomedical Materials Research Part A, 39, 92-101. doi:10.1002/(SICI)1097-4636(199801)39:1<92::AID-JB M12>3.0.CO;2-Q 
[15] Titanium Ti-6Al-4V (Grade 5) (2011) Annealed. http://asm.matweb.com/search/SpecificMaterial.asp?bass $\underline{\text { num=MTP641 }}$

[16] Materal Property Date, (2011) Carpenter MP35N* NiCo-Cr-Mo alloy, $25 \%$ cold reduction. http:/www.matweb.com/search/DataSheet.aspx?MatGUI $\mathrm{D}=\mathrm{b} 78 \mathrm{f} 5 \mathrm{c} 9066924 \mathrm{c} 5 \mathrm{eb} 6 \mathrm{c} 16 \mathrm{~d} 949 \mathrm{f} 27 \mathrm{~d} 928$

[17] Murray, K., Kearns, M. and Mottu, N. (2009) Alloy powders for medical applications. Medical Device Technology, 20, 50-51.

[18] Saha, S., Pal, S. (1984) Mechanical properties of bone cement. Journal of Biomed Mater Research, 18, 435-462. doi:10.1002/jbm.820180411

[19] Litchman, H.M., Richman, M.H., Warman, M. and Mitchell, J. (1978) Improvement of the mechanical properties of polymethylmethacrylate by graphite fiber reinforce-ment. Transaction Orthpadidc Resesrch, 2, 86.

[20] SpecSearch, (2011) AISI type 316L. http://www.efunda.com/materials/alloys/stainless_steels/s how stainless.cfm?ID=AISI Type 316L\&show prop=al 1\&Page Title=AISI $\% 20$ Type $\% 20316 \mathrm{~L}$
[21] Teoh, S.H. (2000) Fatigue of biomaterials: A review. International Journal of Fatigue, 22, 825-837. doi:10.1016/S0142-1123(00)00052-9

[22] ANSYS (2007) Theory reference manual. Release 11.0, ANSYS Inc.

[23] Pilliar, R.M., Blackwell, R., Macnab, I. and Cameron, H.U. (1976) Carbon-fiber reinforced bone cement in orthopaedic surgery. Journal of Biomedical Materals Resesrch, 10, 893-906. doi:10.1002/jbm.820100608

[24] Bayrak, O., Yetim, A.F., Alsaran, A. and Çelik, A. (2010) Fatigue life determination of plasma nitrided medical grade CoCrMo alloy. Materials \& Structures, 33, 303309.

[25] Taira, M., Lautenschlager, E.P. (1992) In vitro corrosion fatigue of $316 \mathrm{~L}$ cold worked stainless steel. Journal of Biomedical Materals Resesrch, 26, 1131-1139. doi:10.1002/jbm.820260903

[26] Budynas, R.G., Nisbett, J.K. (2008) Shigley's mechanical engineering design. 8th Edition, Mc Graw Hill, Boston. 